\title{
REFORMA E READEQUAÇÃO DO HOSPITAL VETERINÁRIO DO CAMPUS II DA UNOESTE - PRESIDENTE PRUDENTE
}

Juliana Domingues Scatolon', Korina Aparecida Teixeira Ferreira da Costa².

${ }^{1}$ Discente do curso de Arquitetura e Urbanismo da Universidade do Oeste Paulista- UNOESTE. ${ }^{2}$ Docente do curso de Arquitetura e Urbanismo da Universidade do Oeste Paulista - UNOESTE

\section{RESUMO}

O artigo intitulado "Reforma e readequação do hospital veterinário do campus II da UnoestePresidente Prudente" expõe o estudo de caso das condições do uso atuais do próprio hospital e as análises de antecedentes de outros hospitais veterinários, estes de referência para o contexto nacional, assim como a análise e proposta de reforma e readequação do hospital veterinário da Unoeste, com a finalidade de melhorar as condições de trabalho dos funcionários e de atendimento aos animais. Para se chegar ao projeto de reforma foram feitos estudos de insolação, ventilação, tipos de aberturas e fluxos do hospital veterinário, a partir disto chegou se a um projeto com as características dos prédios do campus, respeitando as questões de salubridade e facilitando o acesso de animais e pessoas ao interior da edificação.

Palavras-chave: Reforma e readequação, hospital veterinário, insolação, ventilação, salubridade.

\section{INTRODUÇÃO E JUSTIFICATIVA}

O artigo aborda a proposta de reforma e readequação do hospital veterinário da Unoeste localizado no campus II, a partir dos problemas levantados no estudo de caso desenvolvido para o trabalho de conclusão de curso da faculdade de arquitetura da Unoeste.

O hospital veterinário da Unoeste foi construído a partir da necessidade de um local adequado para que os estudantes do curso de medicina veterinária fizessem residência, a construção do H.V. começou em meados do ano de 1989 tendo suas obras concluídas em 1990 e sendo inaugurado em 1991, em decorrência desta urgência na construção o hospital apresenta as deficiências apontadas neste estudo.

O projeto de reforma e readequação teve como objetivo solucionar os problemas de conforto térmico do ambiente construído, dos diferentes fluxos (animais de vários portes, pessoas e materiais) para melhorar as condições de trabalho dos funcionários para que os animais tenham um bom atendimento.

\section{METODOLOGIA}

A investigação se fundamentará na abordagem qualitativa de pesquisa, utilizando-se da pesquisa de levantamento bibliográfico e da pesquisa documental, que segundo Teixeira (2000, p. 137), busca a correlação entre a teoria e os dados, entre o contexto e a ação, a partir da 
compreensão dos fenômenos por meio de sua descrição e interpretação. Para o trabalho com o estudo do tipo de levantamento bibliográfico ocorrerá inicialmente um levantamento das principais produções no contexto nacional de estudos, considerando a peculiaridade do objeto de estudo.

Desse modo, percebe-se que a pesquisa qualitativa vale-se do método indutivo, segundo o qual parte da observação, da análise dos fatos particulares, dos registros para compor um quadro compreensivo para então constituir a generalização universal, ou seja, a teoria. O processo de indução vale-se do princípio do empirismo, no qual o conhecer é dar significado à realidade (KÖCHE, 1997, p. 62).

Foi utilizando como embasamento teórico para as análises do hospital veterinário a titulação "Elementos de Climatização Natural" em que o autor Eduardo Grala da Cunha elenca três condicionantes para uma arquitetura bioclimática.

Estes elementos são o lugar, a cultura e a história, segundo Cunha (2006) o lugar onde se insere o projeto oferece um conjunto de fatores climáticos para adequar a construção, além de auxiliar na forma construtiva e na escolha dos materiais de construção. A cultura tem como objetivo apresentar as possibilidades do fazer humano e compreender as características da arquitetura de cada região compreendendo o espaço habitável.

A história mostra a constante adequação do homem ao entorno e apresenta a evolução e estrutura social, indicando também um rico acervo de características arquitetônicas.

Após a análise de todos estes fatores, foi compreendida a problemática do hospital veterinário e elaborado um projeto arquitetônico de reforma e readequação do H.V. da Unoeste, foram utilizados também as análises de três hospitais, o hospital veterinário de Uberaba de autoria da arquiteta Carmem Silvia Maluf, o hospital veterinário da Universidade Metodista de São Bernardo do Campo projetado pelo escritório Zimbres Associados.

\section{RELEVÃNCIA DOS ANTECEDENTES E A PROPOSTA}

Os hospitais analisados foram o Hospital Veterinário de Uberaba da arquiteta Carmem Silvia Maluf e Hospital Veterinário da Universidade Metodista de São Bernardo do Campo de autoria do escritório Zimbres Associados.

O H.V. Uberaba tem seu projeto composto por blocos dispostos radialmente e projetados a partir de formas geométricas puras como o quadrado e o circulo, cada bloco é destinado a uma atividade desenvolvida no hospital. Este projeto possui ainda áreas verdes internas destinadas a 
circulação de ar e iluminação natural, os corredores possuem como fechamento pérgolas estas voltadas para os pátios internos.

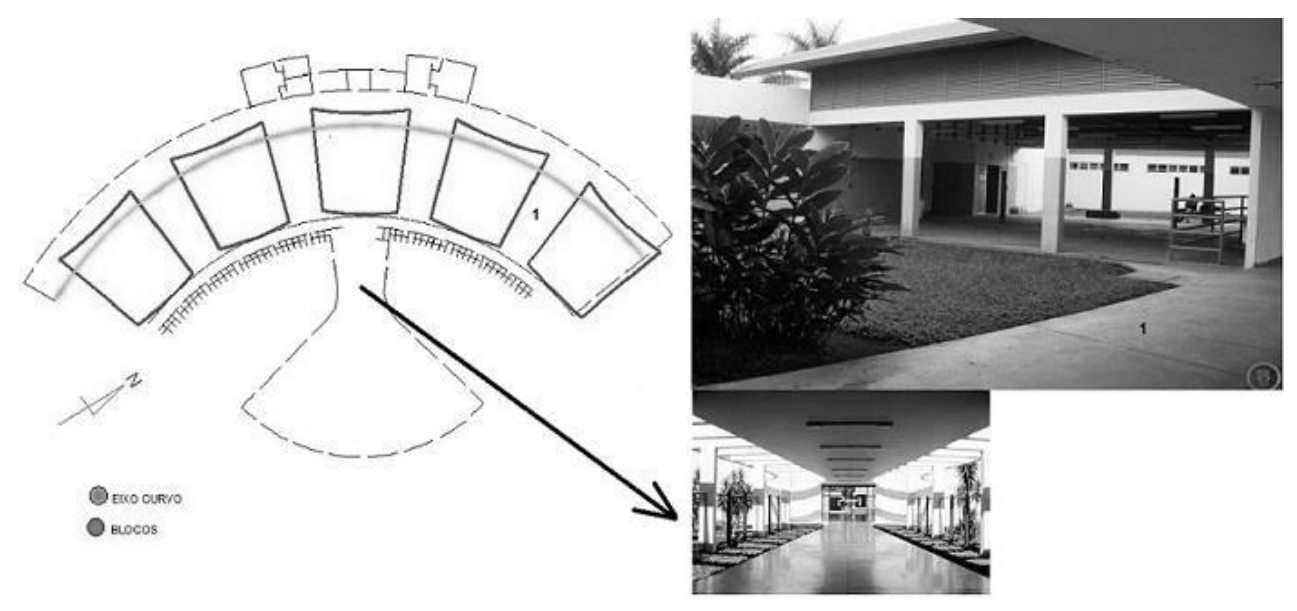

Figura 01. Disposição dos blocos do H.V.U e foto das aberturas

Fonte: Adaptado de Scatolon (2013, p. 31, 35 e42)

Outra característica da edificação importante em hospitais sejam eles veterinários ou humanos é implantação dos centros cirúrgicos, salas de esterilização, ambientes de apoio ao centro cirúrgico como farmácia e laboratórios de analises clinicas, patologias e microbiologia. 0 projeto do H.V.U apresenta uma boa solução para que estes ambientes fiquem próximos sem que haja problemas de fluxo como o cruzamento de materiais infectados com o de materiais limpos. A figura 02 mostra a solução encontrada pela arquiteta no projeto.

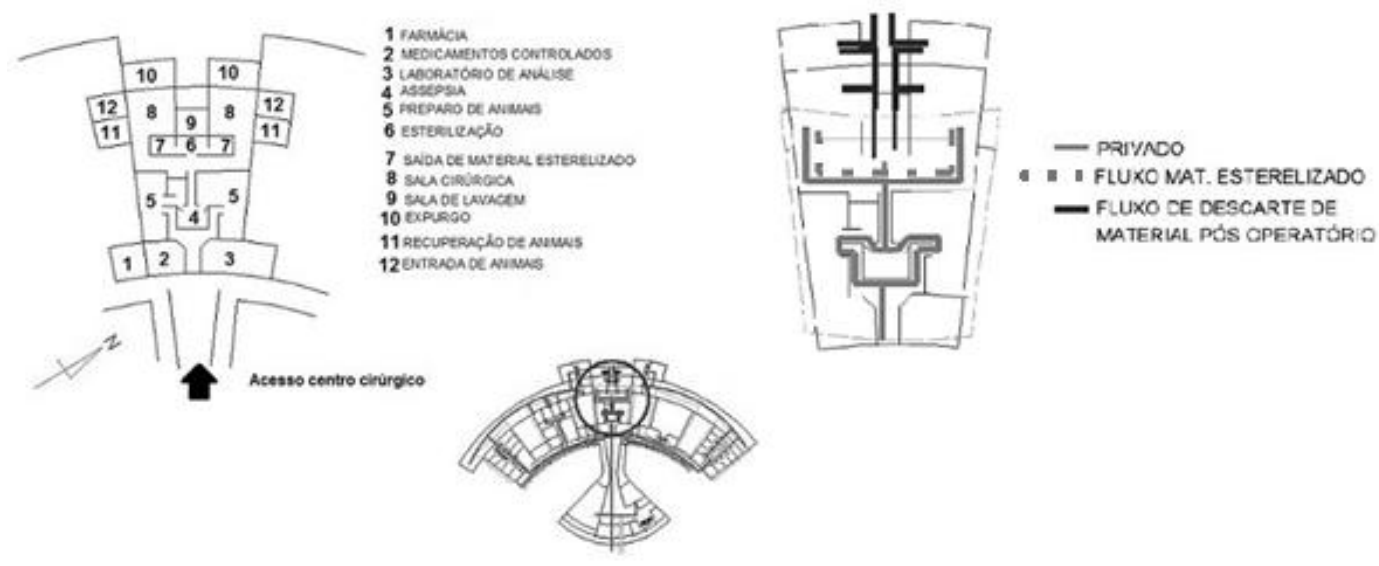

Figura 02. Centro cirúrgico do H.V.U e fluxo de materiais e pessoas

Fonte: Scatolon (2013) 
Outras características levantadas dos antecedentes para elaboração do projeto de reforma estão contidas no projeto do hospital veterinário da Universidade metodista de São Bernardo do Campo de autoria do escritório Zimbres Associados.

O projeto arquitetônico do Zimbres apresenta composição geométrica da fachada com recuos que criam continuidade na edificação e formam aberturas integrando a área externa com a área interna.

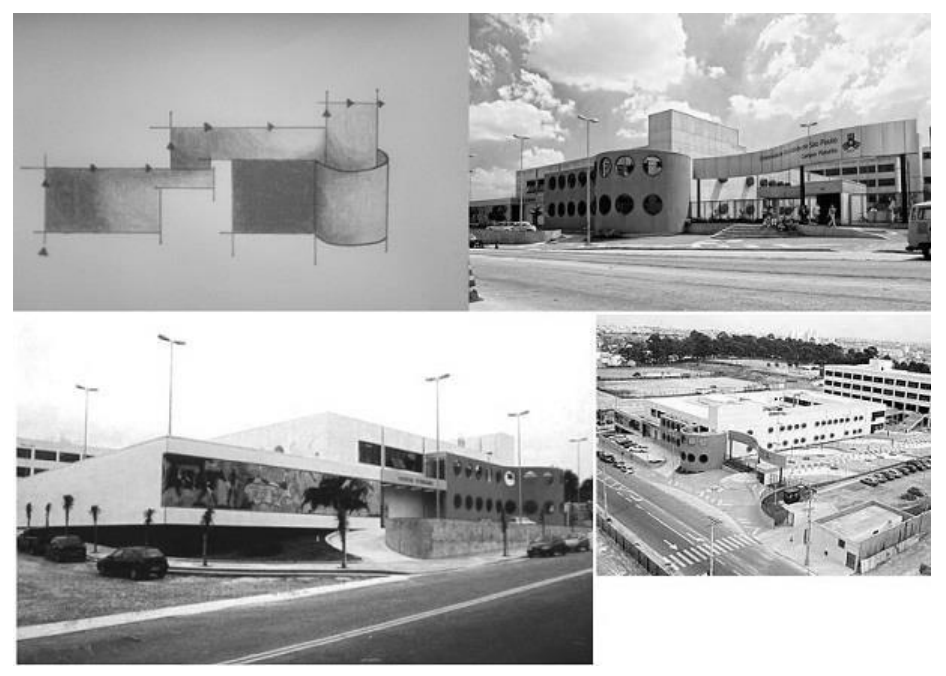

Figura 03. Concepção formal do H.V. da Universidade Metodista

Fonte: Scatolon (2013)

As análises levantaram aspectos para a elaboração de um projeto arquitetônico para hospital, como eixos que norteiem a disposição dos ambientes, formas geométricas puras, aberturas para iluminação e ventilação natural, continuidade da fachada, relação da área interna com a externa, utilização de cores, utilização de pátios internos para separação ou integração dos ambientes. Baseado nestas condicionantes foi elaborado o projeto de reforma e readequação do hospital veterinário da Unoeste.

O hospital veterinário da Unoeste tem sua edificação composta por dois blocos, o primeiro destinado ao atendimento de animais de pequeno porte (cachorro, gato, aves...) e o segundo os animais de grande porte (cavalos e bois). O projeto de reforma propõe alterações apenas no bloco destinado a atendimento de pequenos animais, onde foram observados os maiores problemas.

A proposta de reforma do hospital veterinário da Unoeste seguindo a linha de projeto dos antecedentes buscou manter as formas geométricas da edificação existente, para manter as 
características dos blocos que compõem o campus da universidade. A figura 03 mostra a concepção formal do projeto de reforma
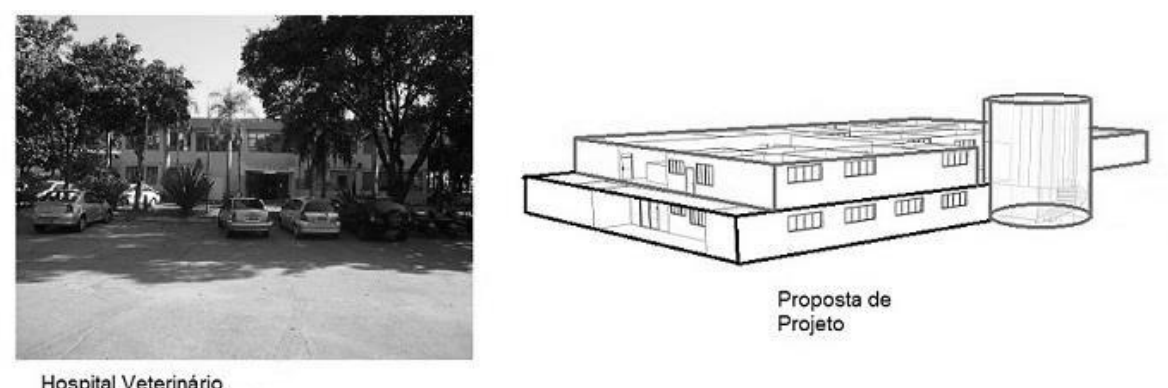

Hospital Veterinário

Figura 04. Prédio existente e Proposta de Projeto do H.V da Unoeste Fonte: Scatolon (2013)

O hospital veterinário possui apenas dois acessos, um principal destinado ao publico e um secundário destinado aos funcionários e médicos do H.V. A proposta de reforma apresenta três acessos, respeitando as normas de acessibilidade para instituições de saúde.
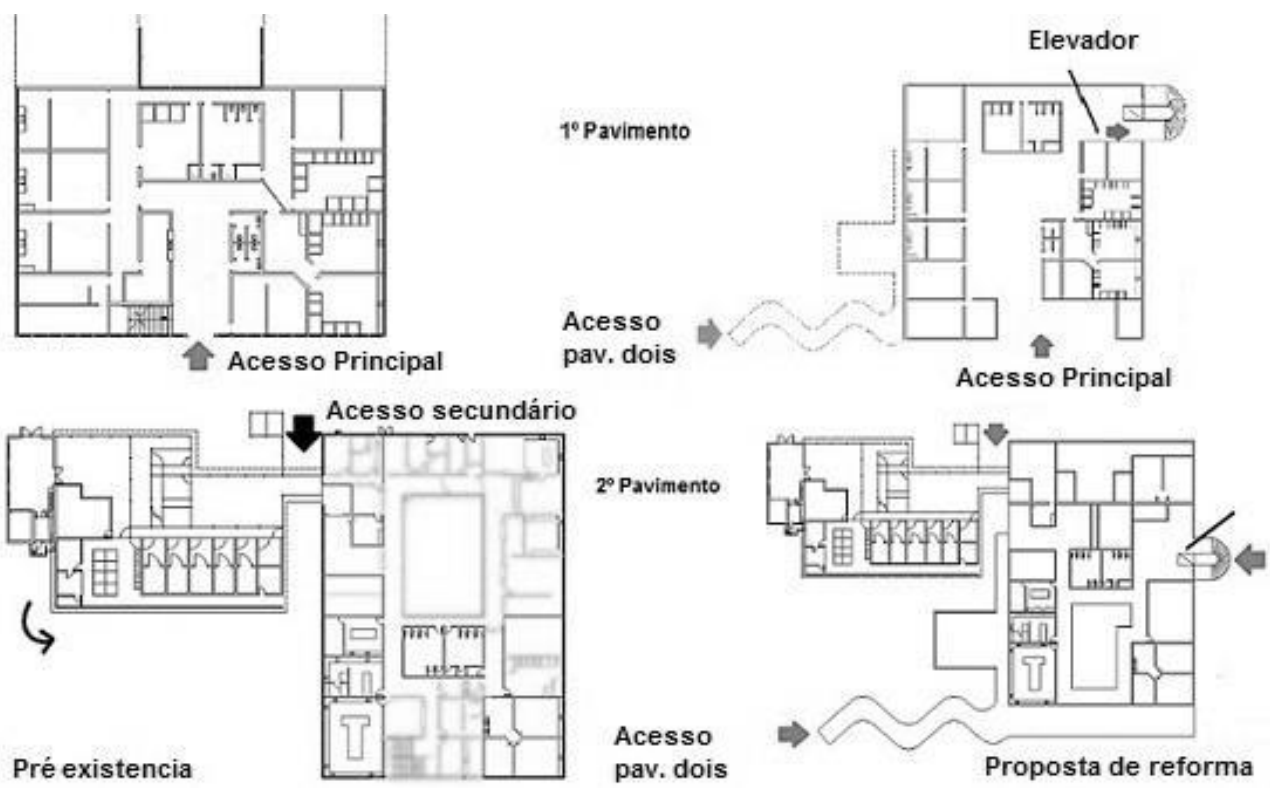

Figura 05. Acessos da pré-existência e da proposta de reforma

Fonte: Scatolon (2013)

Seguindo os princípios de uma arquitetura bioclimática e ainda os estudos dos antecedentes, o pátio existente no hospital veterinário foi remodelado para melhorar as Colloquium Humanarum, vol. 10, n. Especial, Jul-Dez, 2013, p. 402-410. ISSN: 1809-8207. DOI: 10.5747/ch.2013.v10.nesp.000477 
condições de conforto térmico dentro da edificação. Outra proposta com a mesma finalidade foi a elevação da cobertura para auxiliar a troca de ar no interior do prédio.

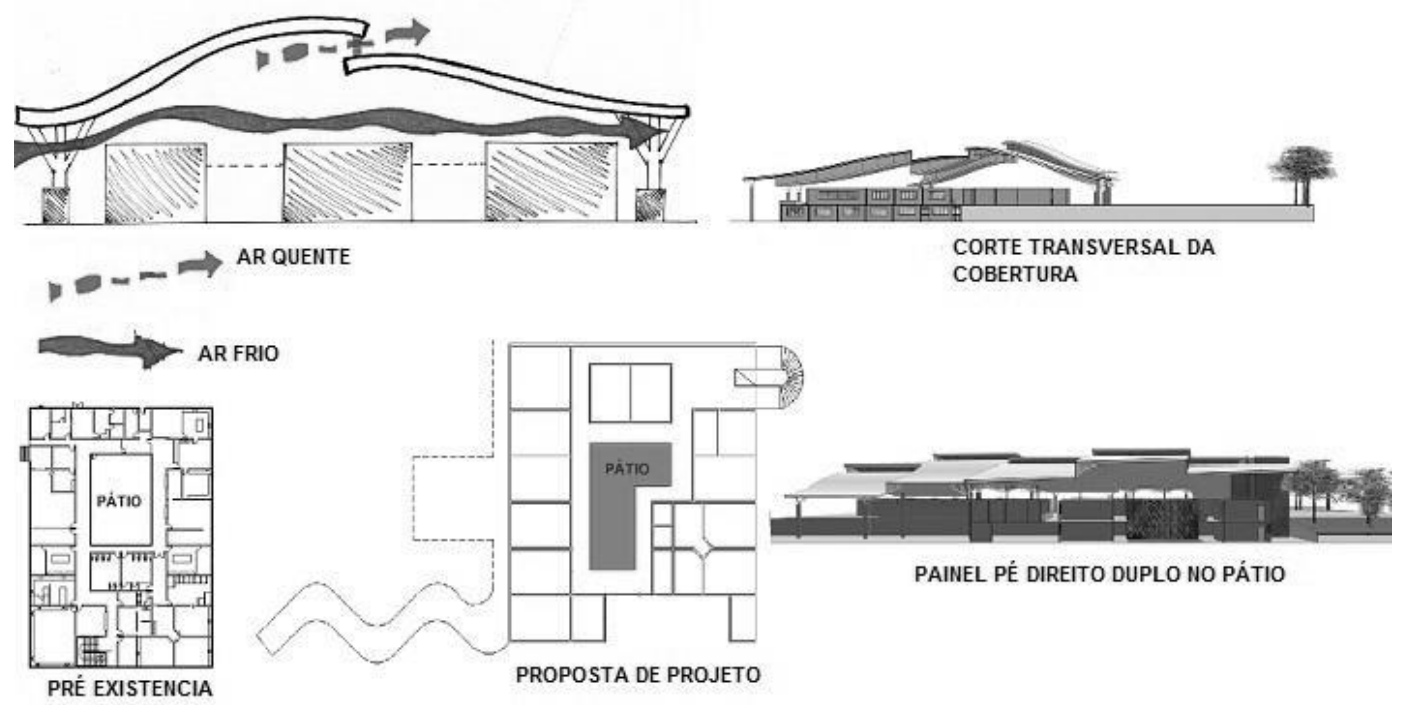

Figura 06. Proposta da cobertura e pátio na reforma do H.V da Unoeste

Fonte: Scatolon (2013)

A proposta de reforma manteve os ambientes existentes na edificação apenas readequando os fluxos para facilitar o atendimento aos animais e as condições de trabalho dos funcionários e médicos. O projeto de reforma reaproveitou o uso de algumas salas do primeiro pavimento e a ampliação do mesmo.

Foi proposto na readequação ampliar os ambientes com salas de aula, posto de enfermagem para preparo de medicação dos animais.
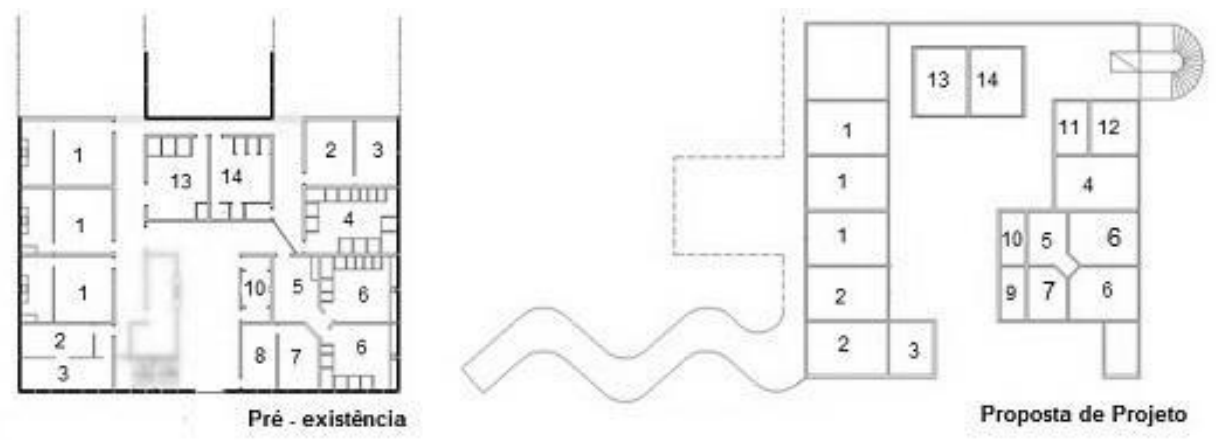
1 Consultóno
2 Sala de aula
3 Sala dos Professores
4 Recuperaçåo
5 Ante-cimara
6 Isolamento
7 Administraçāo
8 Ante-sala
9 DML
10 Banheiros
11 Copa
12 Posto de enfermagem
$13 / 14$ Vestiários

Primeiro Pavimento

Figura 07. Proposta de readequação do primeiro pavimento

Fonte: Scatolon (2013) 
Outro problema apresentado pela edificação é o do fluxo de materiais infectados e materiais esterilizados que são transportados do centro cirúrgico para área de esterilização pelo mesmo corredor. A projeto de reforma remanejou os ambientes propondo solução para estes fluxos.
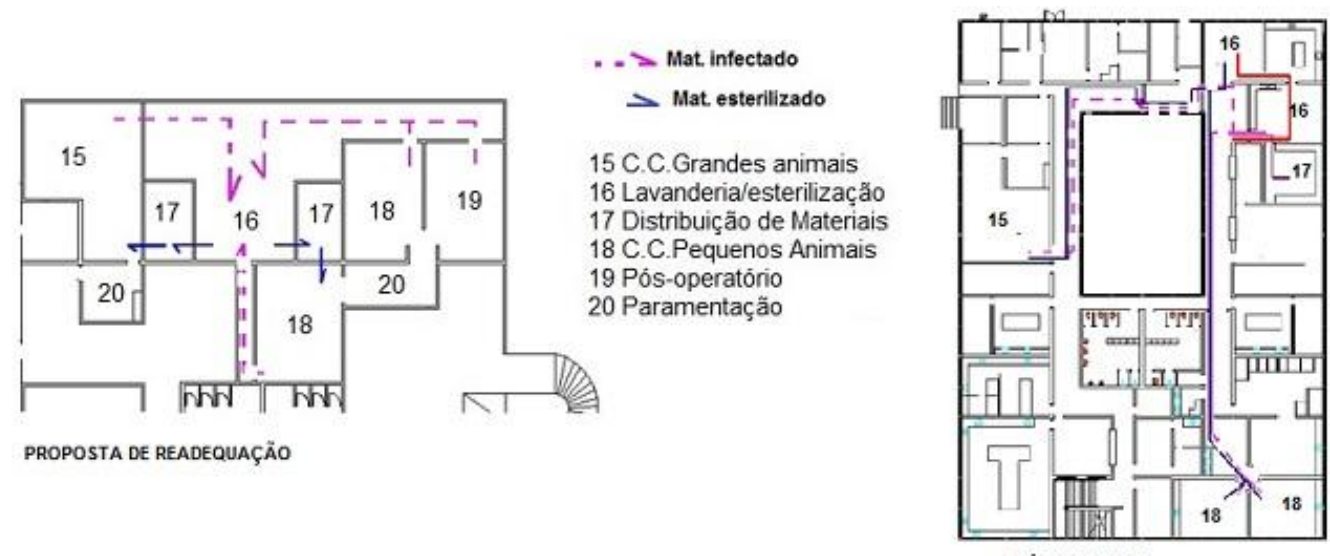

PRÉ EXISTENCIA

Figura 08. Proposta de readequação do centro cirúrgico (2o pavimento)

Fonte: Scatolon (2013)

O segundo pavimento também teve os vestiários realocados para aumentar o pátio interno e readequar os ambientes do hospital veterinário.
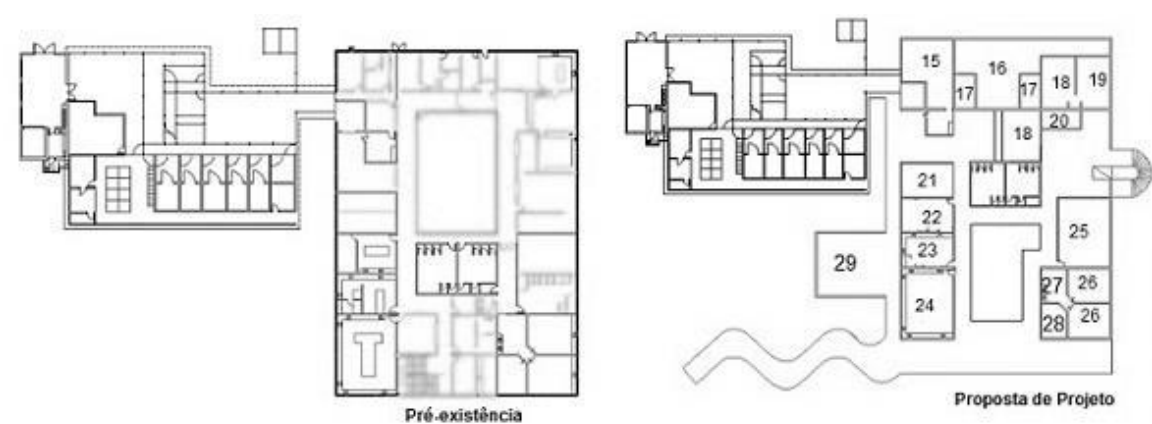

15 C.C. Grandes animais

16 Lavanderia/estenlização

17 Distribuiçăo de Materiais

$18 \mathrm{C}$. C.Pequenos Animais

19 Pós-operatório

20 Paramentação 21 Laboratório de Reproduçăo

22 Laboratório de Parasitologia

23 Laboratório de Microbiologia

24 Laboratório de Analise Clinica

25 Farmácia

26 Isolamento

28 DML

Figura 09. Proposta de readequação do 20 pavimento

Fonte: Scatolon (2013) 
No segundo pavimento estão dispostos os laboratórios e salas de raio $-x$, na proposta de reforma estes ambientes foram readequados para a mesma ala criando um anexo na edificação, com ligação ao H.V de grandes animais.
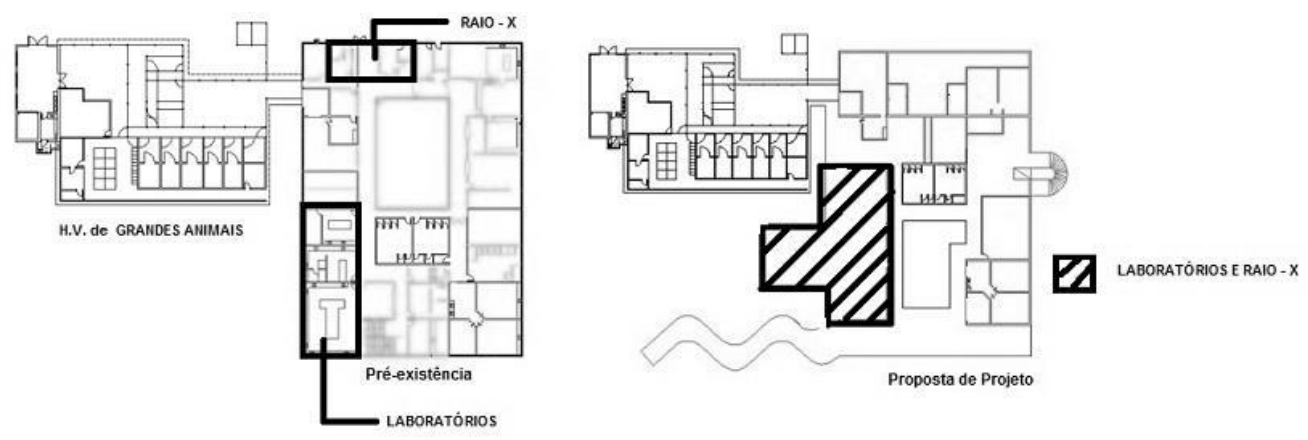

Figura 10. Proposta de readequação dos laboratórios (2ำ pavimento)

Fonte: Scatolon (2013)

A proposta de projeto manteve o padrão formal da universidade, composto por linhas retas, geometria pura e mantendo a implantação da pré-existência, e o paisagismo do local.

\section{CONCLUSÃO}

O projeto de reforma do hospital foi elaborado buscando resolver os problemas de fluxo dos ambientes respeitando a estrutura que compõe o prédio, por tanto a maioria das salas foram mantidas, mantendo o layout dos canis e da fluídoterapia.

A relocação de ambientes possibilitou a implantação de um pátio para diminuição da temperatura do ambiente e umidificação do ar além de criar um espaço de convivência agradável. A elaboração dos acessos possibilitou readequar os fluxos dentro do hospital, de pessoas e animais.

A topografia e a implantação do prédio possibilitou a elevação da cobertura facilitando a renovação do ar dentro da edificação, diminuindo a contaminação do ambiente por bactérias e melhorando a temperatura dentro da edificação.

Este fator fez com que a proposta de readequação do hospital tivesse um resultado harmonioso com o entorno, respeitando o meio ambiente e não alterando a paisagem existente.

$\mathrm{Na}$ área de arquitetura poucas são as práticas voltadas para a área de saúde animal, sendo assim estudos desta forma são relevantes para melhorar as condições de atendimento aos animais e de trabalho aos funcionários. O objetivo de melhorar a infraestrutura do hospital levou 
Encontro de Ensino, Pesquisa e Extensão, Presidente Prudente, 21 a 24 de outubro, 2013

em consideração a incidência solar nas fachadas, direção dos ventos, métodos construtivos e outros, foram suficientes para atender as necessidades do projeto. Pode-se concluir também que apesar de todos os problemas enfrentados pelos funcionários do hospital, estes desempenham suas funções com muita dedicação e amor aos animais.

\section{REFERÊNCIAS}

CUNHA, Eduardo Grala (org.). Elemento de arquitetura de climatização natural: método projetual buscando eficiência nas edificações - Porto Alegre: Masquatro Editora, 2006. 188p.

KÖCHE, J. C. Fundamentos de metodologia científica: teoria da ciência e iniciação à pesquisa. 22. ed. São Paulo: Vozes, 2004.

SCATOLON, Juliana Domingues. Reforma e readequação do hospital veterinário do Campus II da Unoeste - Presidente Prudente - SP, 2013. 113p.

TEIXEIRA, E. As três metodologias. 2a .ed. São Paulo: Vozes, 2000. 